\title{
"SOBRE MUROS E JARDINS": POESIA E VIDEODANÇA
}

\author{
Olga Valeska* \\ Siane Paula de Araújo** \\ Isabel Cristina Vieira Coimbra Diniz ${ }^{* * *}$
}

\begin{abstract}
RESUMO: Neste trabalho propomos uma análise semiótica da videodança "Sobre Muros e Jardins", promovido pelos Grupos de Pesquisa parceiros COMTE do Posling-CEFET-MG e CCODA da UFMG. Este vídeo foi produzido a partir do poema homônimo de Olga Valeska "Sobre Muros e Jardins", presente no seu livro Mundos e Mutações. Como tradução semiótica ele envolve distintas linguagens como a literária, a fílmica e a dança. Nosso objetivo é verificar como tais linguagens foram transpostas para o gênero "vídeodança", em um processo dinâmico de mutação entre distintas texturas de imagens, sons e movimentos rítmicos.
\end{abstract}

PALAVRAS-CHAVE: Videodança. Tradução. Semiótica. Poesia.

\section{Palavras Iniciais}

Neste trabalho propomos uma análise semiótica da videodança Sobre Muros e Jardins ${ }^{1}$, de nossa autoria. O trabalho artístico que analisamos é uma tradução, para videodança, do poema homônimo de Olga Valeska. Para a análise, importanos como nos apropriamos de distintas linguagens presentes no poema, traduzidas na dinâmica de mutações entre distintas texturas de imagens, sons e movimentos rítmicos.

A proposta de criação do vídeo Sobre Muros e Jardins surge a partir da linha de trabalho que vem sendo adotada por pesquisadores pertencentes a dois grupos de pesquisa, a saber: Concepções Contemporâneas em Dança (CCODA) ${ }^{2}$ da Escola de Educação Física, Fisioterapia e Terapia Ocupacional da Universidade

\footnotetext{
* Centro Federal de Educação Tecnológica, Belo Horizonte, Brasil. Imeio: olgavaleska@dppg.cefetmg.br

** Fundação Municipal de Cultura de Belo Horizonte, Belo Horizonte, Brasil; Imeio: sianepaula@yahoo.com.br

*** Universidade Federal de Minas Gerais, Belo Horizonte, Brasil; Imeio: bel.coimbra@hotmail.com

${ }^{1}$ Disponível em: <http://www.youtube.com/watch?v=smg3YECanhA $>$.

${ }^{2}$ Vide: $<$ http://dgp.cnpq.br/buscaoperacional/detalhegrupo.jsp?grupo=03338034BLX6EN>.
}

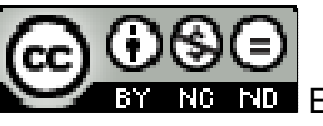

Texto Digital, Florianópolis, v. 10, n. 1, p. 187-201, jan./jul. 2014. ISSNe: 1807-9288 
Federal de Minas Gerais (EEFFTO-UFMG), um dos projetos, ou desdobramentos do Programa de Dança Experimental (PRODAEX) da mesma instituição; Núcleo de Pesquisa Corpo, Movimento e Tecnologia (COMTE) ${ }^{3}$, que trabalha com Semiótica e Poéticas do Corpo e do Movimento no Programa de Pós-Graduação em Estudos de Linguagens do Centro Federal de Educação Tecnológica de Minas Gerais (POSLING-CEFET-MG).

Essa perspectiva de trabalho engloba, prioritariamente, a tradução em dança de obras literárias a partir de uma análise semiótica como uma via de acesso. Dessa forma, a criação e a produção gerada é fruto dos processos de leitura de textosescritos que se tornam textos-dançados. Esse processo também abarca 0 caminho poético-corporal próprio da dança experimental que envolve a busca de uma dança própria do sujeito dançante, crítico e analítico diante do que se produz.

Nesse contexto, importa citar alguns dos trabalhos anteriores realizados, tais como Diamantina em Performance: Minha Vida de Menina (2010) ${ }^{4}$, que foi uma proposta de tradução poético-corporal do romance Minha Vida de Menina, de Helena Morley. Ou o trabalho Dança ao Pé da Letra (2009) ${ }^{5}$, que buscou transpor os significados dos sentidos da palavra "oposição" para a dança. Dentro desse mesmo horizonte de pesquisa inclui-se também o projeto "Mutações sobre um estranho corpo" (2011), desenvolvido no Festival de Inverno de DiamantinaUFMG que buscou uma leitura poético-corporal do poema "Corpo Estranho" publicado no livro Mundos e Mutações, de Olga Valeska.

Nesses trabalhos de pesquisa poética, não existe um processo coreográfico desenvolvido a priori, mas sim a elaboração prévia de um projeto geral de experimentação de movimentos poéticos corporais. E estes também podem se pensados como fruto da interação do corpo com o ambiente, ou melhor, com os espaços escolhidos a partir de sua potencialidade estética no que se refere a

\footnotetext{
${ }^{3}$ Vide: $<$ http://dgp.cnpq.br/buscaoperacional/detalhegrupo.jsp?grupo=8704803GPKT1AM>.

4 Disponível em: <http://www.youtube.com/watch?v=0ngdHDvgi-0> (parte 01) e $<$ http://www.youtube.com/watch?v=W5-LF1Wto6w> (parte 02).

${ }^{5}$ Disponível em: <http://www.youtube.com/watch?v=H4IJEFTLBO4 $>$.
} 
aspectos arquitetônicos, sons ambientes e riqueza de cores e cheiros. Além disso, esses espaços são escolhidos por suas peculiaridades e por sua história.

Sobre esse caminho experimental, vale ainda ressaltar, a influência de dois projetos: Dança na Mochila ${ }^{6}$, que também é parte da pesquisa que integra parte do doutorado de Isabel Coimbra cuja proposta é traduzir, segundo a semiótica greimasiana, em experimentos de videodança o espetáculo $A$ Sagração da Primavera de Pina Bausch; e o projeto Dança Itinerante do PRODAEX que acontecia por meio de intervenções em distintos espaços cotidianos como ruas, monumentos históricos, praças, igrejas, escadarias e outros locais e de variadas cidades, estados e até países com o propósito de mobilizar uma dança a qual se daria no instante performático do improviso.

O objetivo do presente trabalho, como já foi dito, é analisar um dos produtos audiovisuais desse esforço coletivo, o vídeo Sobre Muros e Jardins, produzido pela dançarina e pesquisadora, Siane Araújo. O trabalho consistiu em uma tradução semiótica de um poema expresso em linguagem escrita, para a linguagem audiovisual em um texto de videodança.

Mais especificamente, o processo de criação de Sobre Muros e Jardins partiu inicialmente da proposta de traduzir outro dos trinta e três poemas do livro Mundos e Mutações da poetisa Olga Valeska. O espaço escolhido para as filmagens experimentais foi a cidade de Curitiba, no estado do Paraná, em oportunidade surgida durante o Congresso da ABRALIN de 2011. Os "cenários" da cidade, em específico os belos jardins e os ladrilhos das calçadas da Praça Santos Andrade, que desenham flores de pedra no chão, ditam os sentidos que "gritavam" do poema por uma dramaturgia dançada. Estava posta, assim, a matéria-prima para a produção da vídeodança sobre a obra literária de referência. Importa ressaltar que a obra contou com a gratuita colaboração de filmagem de Cleide Cruz, professora do Curso de Licenciatura em Dança do Instituto Federal

\footnotetext{
${ }^{6}$ Disponível em: <http://dancanamochila.wordpress.com/>.
} 
de Brasília, bem como, do artista visual Luhan Dias no processo de edição e montagem dos planos.

Os experimentos foram realizados em quatro diferentes lugares da praça escolhida os quais deram origem aos distintos planos da vídeodança. Todas as experimentações geraram registros audiovisuais que passaram pelo seguinte processo de edição: seleção e sequenciação de cenas por mecanismos de corte e colagem, aplicação de efeitos visuais, inserção de créditos e afins que ditam a formatação final da obra, bem como da inserção do design sonoro, que participou da constituição dos sentidos das cenas.

\title{
Do poema e da dança
}

\author{
SOBRE MUROS E JARDINS ${ }^{7}$ \\ Não me pergunte por meu rosto \\ - Meu rosto fui eu quem forjei. \\ Não vai querer sondar meus traços \\ com suas delicadas lembranças torturadas. \\ Não me pergunte pelo que sinto. \\ - Meus sentimentos se perderam na violência \\ do sentido concreto das palavras, das pedras e de ferros mortais \\ Meu nome? Não me pergunte qual seja \\ Sabe que eu sou estrangeira? \\ que nasci do mar, do fogo ou da lama machucada do seu \\ jardim \\ Sabe que fugi? e que me escondi nem sei bem onde? \\ pra não sangrar, ferida de lágrimas \\ ... afiadas demais.
}

Como já foi dito, o poema é parte de, "Mundos e Mutações". Trata-se de uma obra poética que busca uma linha cosmológica inspirada em diversos mitos de origem, mantendo, porém, elementos do cotidiano de vidas comuns. O texto, assim, transita entre dois pontos de vista: o micro e o macrocosmo, focalizando a

${ }^{7}$ VALESKA, 2010, p. 57.

Texto Digital, Florianópolis, v. 10, n. 1, p. 187-201, jan./jul. 2014. ISSNe: 1807-9288 
experiência humana em seu aspecto subjetivo e arquetípico a um só tempo. $O$ livro se divide em quatro partes: A Noite, A Terra, Os homens e Os Visionários. $O$ conceito de mutações é tomado nessa obra poética como operador do processo criativo, sendo que cada poema potencializa além da duplicidade de leitura apontada anteriormente, uma transposição para objetos visuais que traduzem texturas, sons e ritmos para a linguagem visual.

O poema que serviu de ponto de partida para a produção da vídeodança que analisamos nesse trabalho integra a terceira parte do livro e faz alusão a uma "queda original" ou a uma ruptura com a segurança e as certezas de um espaço familiar ou paradisíaco. Estabelecendo uma relação intertextual com o livro Gênesis, o nome, "Sobre muros e jardins" já traz a ambivalência presente nesses espaços que paradoxalmente acolhem e aprisionam a um só tempo.

Ora, sabemos que o texto bíblico coloca na origem da humanidade, que um casal cujo varão é induzido ao erro por sua companheira, enganada por uma serpente. Ambos acabam expulsos do Paraíso e da convivência cotidiana com um Deus Pai. No poema, ao invés de um protagonista masculino (Adão), uma voz poética feminina anuncia sua "fuga" de um espaço de afeto (maternal?), um jardim de "lama machucada". A protagonista do drama original não é vítima passiva de um erro, mas escolhe a separação como forma de sobrevivência diante de um poder que a arrebata e domina a um só tempo. Nesse aspecto, o poema afirma a liberdade de escolha na esfera ontológica e existencial.

Porém, essa escolha é contraditória e irônica a um só tempo. A voz poética acaba afirmando uma diferença nascida da estranheza que se reconhece fruto de uma ferida alheia: "Sabe que eu sou estrangeira?/que nasci do mar, do fogo ou da lama machucada do seu/ jardim". Sua identidade é afirmada, ironicamente, da negação que surge de um sofrimento extremo: uma ferida exposta na materialidade da dor de um "Outro": um antagonista ausente e onipotente a um só tempo. 
A primeira imagem que surge no vídeo é um cruzamento de caminhos que divide um jardim público. A bailarina surge caminhando de maneira firme, ingressando nesse jardim que lembra uma pintura. A vivacidade das cores e a textura imprecisa das formas que a envolvem e constituem parecem fazer alusão a um espaço imaginário que bordeja a evasão e o sonho. Tece-se aí a relação com as mutações de cenário, cor, textura e movimentações que se fazem em um jogo com os movimentos de câmera (zoom, animações, recuo, etc.) e com a música. As imagens em movimento e som refletindo o "como" o "eu feminino" do poema interpreta o mundo, em forma de videodança. Nessa cena, é bastante significativo o fato de que a protagonista, com seus passos firmes, não parece hesitar na escolha do caminho da esquerda, assinalando a face criativa e emocional do psiquismo humano. A foto, a seguir, busca exemplificar este momento:

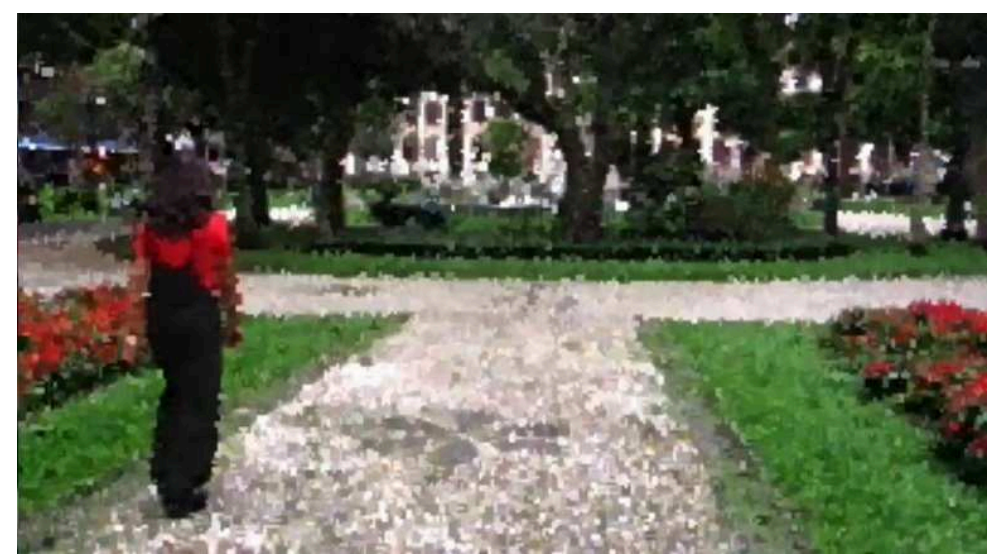

Fig. 1 - Cena 01: A entrada no jardim

Nunca se deve esquecer, porém, que esse espaço aparentemente paradisíaco é fruto de uma edição, com um efeito de "pintura a óleo". Nesse aspecto, consonante com o poema, a escolha que, na cena, parece definida por uma decisão livre, acaba contaminada por uma ambivalência irônica que torna relativas as fronteiras que demarcam a liberdade individual e o limite que se impõe sobre cada escolha humana. Essa ambivalência fica evidente na movimentação do corpo da bailarina: por um lado, a dança caracteriza-se, de um modo geral, por elementos súbitos de aspecto firme, por outro lado, as 
sequencias gestuais encadeiam os passos de uma maneira fluida, caracterizando a dimensão livre da ação do corpo no espaço.

A música, de autoria de Isabel Coimbra mixada e reeditada por Siane Araújo, dialoga com o texto imagético e de movimento da dança no vídeo quando enuncia sentidos do poema que se referem à própria condição em que se encontra o "eu" feminino do poema: a ambiguidade entre o querer se libertar e a certeza de se ser prisioneiro do "mundo" ou do jardim. Esta relação reflexa é dada no design sonoro pela música de Isabel Coimbra. Ela se baseia em sons de espelhos quebrando e envolve toda a representação de quebra e ruptura, mas que é invertida ${ }^{8}$ durante 0 processo de edição e acrescentada de uma célula musical ${ }^{9}$ exibida de forma simultânea a essa música que se torna "de fundo", repetindo-se a quase todo o vídeo. Dessa forma, tem-se a rebeldia e a manifestação de liberdade dada nos sentidos sonoros de ruptura e na travessia para um outro espaço do jardim, quiçá uma representação de tal liberdade idealizada, porém essa liberdade é limitada e condicional por um aprisionamento evidenciado nos signos cíclicos do trecho que perdura na música do vídeo.

Importa ressaltar que a célula musical é composta, basicamente, por quatro notas que se repetem em um desenho circular. Essa circularidade também parece dialogar com a perfeição geométrica do jardim. Porém se a geometria regular dos círculos, triângulos e quadrados assinalam a perfeição, ela também pode ser pensada como um muro que protege e aprisiona o corpo da bailarina. $\mathrm{O}$ corpo fica, assim, dividido entre a liberdade de um jardim imaginário, perfeito, e os muros de uma geometria arquitetada por uma vontade alheia.

O vídeo se divide cinco cenários definidos por tratamento digital, recortes e colagens, ambientados pelo design sonoro. Assim podemos perceber duas temporalidades distintas: o agora da dança e o agora que se desenrola na leitura do vídeo em seu formato final. Nesse aspecto, o corpo que dança, no momento da performance, não interage com a paisagem presente no texto definitivo,

\footnotetext{
${ }^{8}$ Recurso disponível pelo programa WavePad Sound Editor.

${ }^{9}$ Célula musical criada e produzida a partir de recursos eletrônicos de composição.
} 
editado. O corpo visto no vídeo não escolhe, assim, seu espaço de expressão, mas atravessa os cenários editados a despeito de seus próprios gestos, musicalidade e do desenho de seus passos. Estes que buscam, por meio das fusões entre as distintas narrativas poéticas do poema e da dança, gerar semioses de sentido entre o corpo, o espaço e o texto - imagético e sonoro.

O poema procura retratar a violência das rupturas que se estabelecem nas construções de identidade, mas também faz alusão à cisão entre a experiência do corpo e o mundo da linguagem, com sua dimensão reflexiva e questionadora: "Meus sentimentos se perderam/no sentido concreto das palavras, das pedras e de ferros mortais".

No texto escrito, temos, dessa forma, um corpo dividido entre a vitalidade da existência da unidade original e a perplexidade de se saber mortal e em estado de solidão no mundo que é matéria bruta, mas que também é signo e sentido abstrato. No vídeo, vemos um corpo que dança, paradoxalmente alheio ao espaço que ocupa e intensamente presente à paisagem que o acolhe, seja ela um jardim florido ou um ladrilho de pedras no calçamento urbano.

O corpo que dança é um corpo tornado signo de uma linguagem que vai além dele próprio; e essa marca é reiterada na virtualidade de um texto fílmico. Esse processo tradutório obriga a dança a se dizer através de outros signos. E o corpo que dança acaba se constituindo e se expressando através de imagens dispostas por uma ordem ditada por recursos alheios a ele mesmo, num meio digital.

$\mathrm{Na}$ segunda parte do vídeo, a paisagem parece envelhecer, com cores apagadas, e a personagem parece sondar esse espaço antigo (lugar de memória?), medir sua extensão e profundidade, como se descobrisse e testasse seus limites. Seus movimentos são paradoxalmente rápidos e ondulantes, buscando representar toda a "falta de cor" com que o mundo Ihe sorri. E a bailarina encerra a sequência com um salto que atravessa o próprio cenário e a leva de volta ao espaço anterior, colorido e de formas imprecisas: uma forma de interrogar também o espectador sobre qual seria, de fato, o seu espaço: memória, imaginário ou 
mundo concreto. Importa lembrar que o poema também sugere tal ambivalência como na passagem: "Sabe que fugi? e que me escondi nem sei bem onde?". Os frames seguintes buscam ilustrar essa passagem:

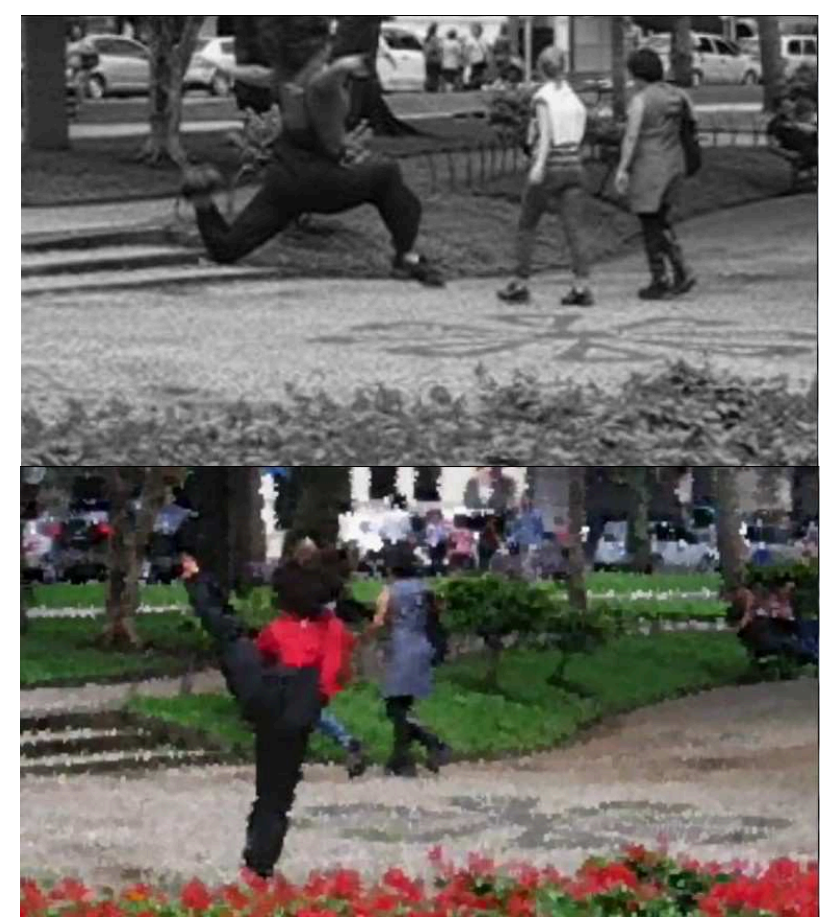

Fig. 2 - Cena 02: Passagem para o jardim colorido

Nesse cenário, os movimentos da bailarina se amplificam com giros e oscilações fortes dos braços e do tronco até que a câmera enquadra a imagem de um conjunto de flores que se desvanecem dando espaço para as flores formadas pelas pedras da calçada de cores envelhecidas e apagadas. Os frames na sequencia buscam ilustrar visualmente essa transição: 


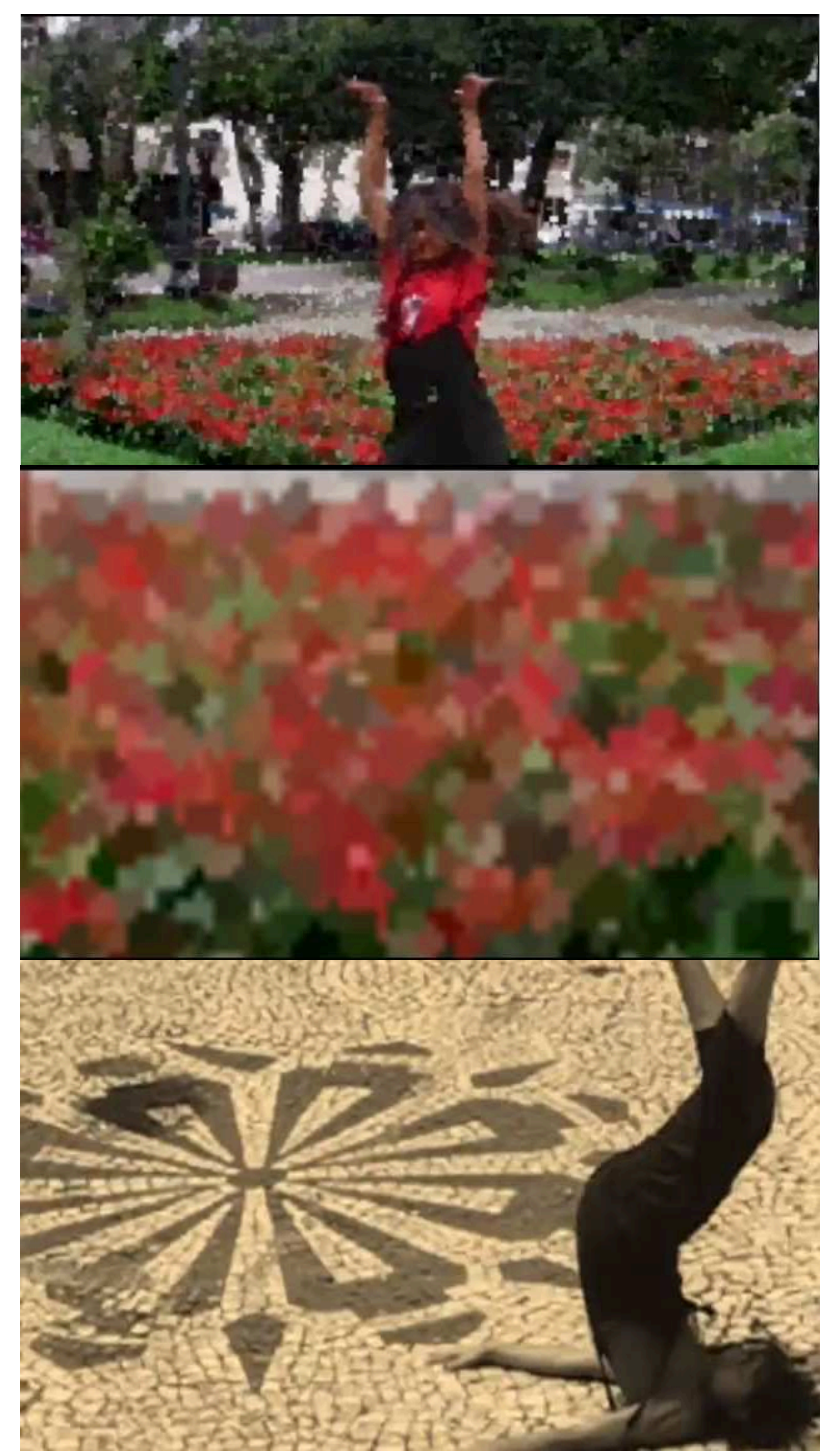

Fig. 03 - Cenas 03 e 04: Passagem para o "jardim de pedras"

Nesse trecho a coreografia acontece com movimentos executados no solo. $\mathrm{O}$ corpo da bailarina parece testar os limites de sua elasticidade enquanto vivencia 0 toque das pedras. A edição do vídeo expõe o cenário de cores amareladas que assumem o sentido de terra e mineral, presentes no poema, ao mesmo tempo em que mantém a relação desse espaço com o que de fato é: uma calçada: ambiente de trânsito, passagem e de visibilidade. Em outro aspecto, observa-se a interação da "voz feminina" do poema com um "outro" ao qual ela se dirige, como se nota no trecho: "Não me pergunte pelo que sinto". Um sujeito poético que procura chamar a atenção para si a partir de um "outro" representado, talvez, pelo próprio espaço que a constitui. 
Nesse trecho, o tema nuclear da música desaparece ficando apenas outro ciclo musical, o de uma música que soa como um "sopro", mas ao mesmo tempo parece ressoar uma mágoa teimosa, traduzindo a inconformidade da voz do poema quando se "nega" a qualquer interlocução, como se nota nas passagens: "Não me pergunte por meu rosto/ - Meu rosto fui eu quem forjei./Não vai querer sondar meus traços/com suas delicadas lembranças torturadas". Estabelece-se, assim, um diálogo paradoxalmente monológico: nega as interrogações antes que elas se formulem ao mesmo tempo em que se nega a dar as respostas supostamente esperadas.

Cabe notar que a construção dialógica do poema parece ser ambivalente: um mesmo sujeito poético se pronuncia em versos precedidos ou não de travessão. Essa estrutura coloca em questão a própria fronteira entre o "eu" que se constitui a partir da afirmação de sua diferença e a totalidade absoluta de um Ser original que lega a sua materialidade ontológica. No vídeo, esse outro é representado tanto pelo jardim público quanto pela calçada de flores de pedra: dois espaços urbanos que, como construções humanas parecem questionar a validade do Édem paradisíaco, divino, para afirmar o estado de queda do corpo que dança.

Lembramos que o sentido etimológico do nome Adão, está associado à ideia de barro. É bastante significativa a enumeração, no poema, dos elementos da natureza como matéria original, seguidos da expressão "lama machucada de seu/jardim". Nesses versos, a vida surge no momento da constatação afirmativa do sofrimento original inerente à separação, que podemos pensar como um gesto afirmativo: "sabe que sou estrangeira? Que nasci do mar, do fogo (...)", mas também da constatação de um sofrimento insuportável, porque sempre alheio "(...) ou da lama machucada de seu/jardim".

Observe-se que a palavra "jardim" aparece isolada em um único verso. Assim, o gesto livre de fugir rumo à liberdade também constitui um exílio. Da mesma maneira que Adão, o sujeito poético acaba optando livremente pelo seu próprio destino: a solidão. Porém, diferente do protagonista bíblico, essa voz feminina não busca um conhecimento, mas o esquecimento: de um saber dolorido demais: 
"Sabe que fugi? e que me escondi nem sei bem onde?/pra não sangrar, ferida de lágrimas/... afiadas demais".

Na última parte do vídeo, a mais breve, a dança muda novamente de cenário e o corpo ressurge e desaparece em um lance de segundos, entre as flores do jardim colorido, movido por um gesto de quem procura se esconder, mas, ao mesmo tempo, se mostrar, se expressar. Assim como, a mudança de cenário também representa a própria volta de um lugar talvez apenas imaginado e lembrado para outro presente ou esquecido.

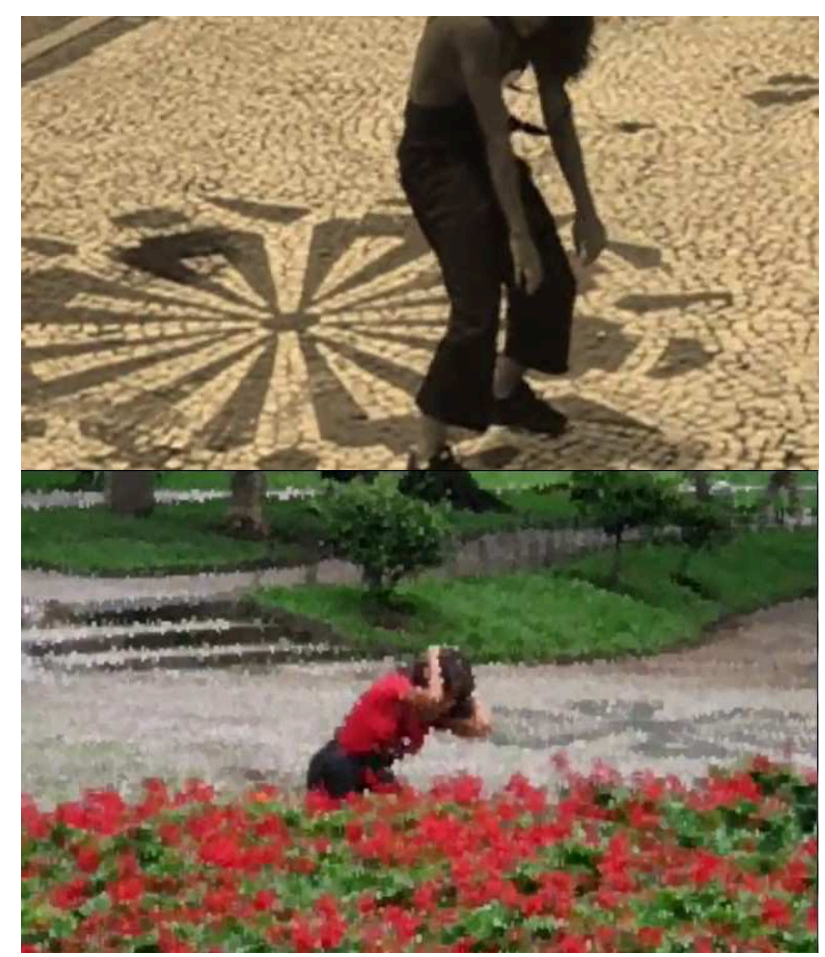

Fig. 04 - Cena 05: Mudança de cenário e finalização

\section{Considerações finais}

Flores de pedra, flores de um jardim colorido de formas paradoxalmente geométricas e imprecisas constituem o espaço com o qual o corpo interage em uma coreografia marcada por giros e pequenos saltos, parecendo expressar paradoxalmente a alegria da liberdade assumida e a angústia de se saber 
prisioneiro a despeito de qualquer escolha. No poema, a memória funciona como lastro de pedra que afoga e parece querer engolir o sujeito poético com sua delicadeza. E o sujeito constitui na própria palavra disposta em diálogo, um espaço de fuga e exílio. Um exílio de si mesmo e do outro que o constitui como lugar de sofrimento e prisão. Na coreografia, o corpo atravessa os jardins como se ambos (corpo e jardim) fossem simultâneos, abertos para experiências transcendentais e cotidianas a um só tempo. O percurso gerativo de sentido no nível profundo do texto em dança se constrói e se refaz a cada cena criando laços entre o enunciador e o enunciatário. Essa relação também constituída pela possibilidade da dança no ciberespaço e a semiótica como membrana permeável ao desvelamento de sentidos e significados de espaços movediços.

Assim, a mutabilidade entre as relações do "eu" e do "mundo" no poema também convergem com as mudanças e variações no vídeo: rápidas, constantes e "resignificantes", ou seja, os espaços e seus "modos de uso", como da calçada, por exemplo, se tornam uma "vitrine dançante" e de possibilidades infinitas de interação e leitura.

Como já foi apontado, o trabalho que analisamos resultou de um processo de edição a posteriori, o que caracteriza o gênero Vídeodança. Neste, diferentemente da dança filmada, o trabalho de pré-produção, produção e, pincipalmente, de pós-produção, caracterizado aqui pela "edição", interfere de maneira marcante no resultado final, permitindo cortes e tratamento de imagens, assim como a edição e inclusão da música e outros elementos externos à dança propriamente dita. Assim, no caso da coreografia analisada, observam-se mudanças significativas no tratamento das imagens originais que sofreram cortes e colagens.

O corpo é presença no momento mesmo da performance coreográfica, mas é também concepção fílmica nas imagens editadas em vídeo. O concreto e o imaginário; a cor e o desbotamento; a presença e a ausência se alternam nas cenas do vídeo e nos movimentos da bailarina em uma linguagem hibrida e móvel que atravessa os signos sonoros e visuais. Pode-se dizer, assim, que o vídeo 
compõe uma Gênesis além do texto bíblico e além do próprio poema, redimensionando os sentidos e se apropriando de formas e imagens arquetípicas e cotidianas a um só tempo.

\section{"SOBRE MUROS E JARDINS": POETRY AND DANCEMOVIE}

ABSTRACT: In this work we propose a semiotic analysis of "dancemovie" "Sobre Muros e Jardins," realized by the partners researches groups COMTE of the Posling-CEFET-MG and CCODA of the UFMG. This art was produced from the poem by Olga Valeska "Sobre Muros e Jardins", this in his book "Mundos e Mutações" and thereby involving different languages such as literary, film and dance for the translation intersemiotic. Our wait is to see how such language was appropriate for the genre "dancemovie" in a dynamic process of mutation between different textures of the images, sounds and rhythmic movements.

Keywords: Dancemovie. Translation. Semiotic. Poetry.

\section{REFERÊNCIAS}

ALVARENGA, Arnaldo Leite de. Dança Moderna e educação da sensibilidade: Belo horizonte (1959-1975). 2002. Dissertação de Mestrado - Faculdade de Educação, Universidade Federal de Minas Gerais.

KATZ, Helena. A dança, pensamento do corpo. In: Novaes, Adauto (Org). 0 homem-máquina: a ciência manipula o corpo. São Paulo: Companhia das Letras, 2003.

LABAN, Rudolf von; ULLMANN, Lisa. Domínio do movimento. 2. ed. São Paulo: Summus, [1978].

LAMBERT, Marisa Martins. Expressividade Cênica pelo Fluxo Percepção/Ação: O Sistema Laban/Bartenieff no desenvolvimento somático e na criação em dança. Campinas: UNICAMP, 2010. 279 pag. Tese (Doutorado) Programa de Pós-Graduação em Artes, Instituto de Artes, Universidade Estadual de Campinas, Campinas, 2010.

LARA, Glaucia Muniz Proença; MATTE, Ana Cristina Fricke. Ensaios de semiótica: aprendendo com o texto. Rio de Janeiro: Nova Fronteira, 2008.

PEREIRA, Ana Cristina Carvalho. Linguagem e Cognição: uso de Analogias e Metáforas no Ensino do Balé em Escolas de Belo Horizonte. 2005. Dissertação de Mestrado - Programa de Pós-Graduação em Educação Tecnológica do CEFETMG, Belo Horizonte.

RENGEL, Lenira Peral. Dicionário Laban. São Paulo: Annablume, 2003. 
SANTAELLA, Lucia. Semiótica Aplicada. 1. ed. São Paulo, 2002.

. Matrizes da Linguagem e Pensamento. São Paulo: lluminuras, 2009.

VALESKA, Olga. Mundos e Mutações. Belo Horizonte: Anome, 2010.

Texto recebido em: 14/07/2014. 